\title{
MEAL INDUCED OXIDATIVE STRESS LEVELS IN CONTROLLED AND POORLY CONTROLLED DIABETES
}

\author{
SULEKHA SINHA ${ }^{1 *}$, POORNIMA A MANJREKAR ${ }^{2}$, ANUPAMA HEGDE ${ }^{2}$, RUKMINI MS $^{2}$ \\ ${ }^{1}$ Department of Biochemistry, IQ City Medical College, Durgapur - 713 206, West Bengal, India. ${ }^{2}$ Department of Biochemistry, Kasturba \\ Medical College, Mangalore - 575 004, Karnataka, India. Email: drsulekhasinha@gmail.com
}

Received: 16 February 2017, Revised and Accepted: 09 March 2017

\section{ABSTRACT}

Objective: The postprandial (PP) metabolic derangements are accentuated in Type 2 diabetes and are important risk factors for cardiovascular disease since they induce oxidative stress and endothelial dysfunction. The aim of the study was to analyze meal induced oxidative stress levels in controlled and poorly controlled diabetes.

Methods: Total 60 Type 2 diabetic patients on oral hypoglycemics of duration 5-15 years were divided into two groups based on hemoglobin A1c values ( $\leq 7.5 \%$ for controlled/Group 1 and $\geq 7.6 \%$ for poorly controlled/Group 2). They were assayed for serum/plasma glucose, thiobarbituric acid reacting substances (TBARS) and oxidized low-density lipoprotein (ox-LDL) parameters both in fasting and 2 hrs post meal in both groups. Statistical analysis was performed using independent t-test between the groups and paired t-test within each group.

Results: The PP TBARS were found significantly higher in both groups, whereas no significant difference between the two groups. The ox-LDL levels were found similar at two points of time in both groups.

Conclusion: An exaggerated PP oxidative stress levels are associated with diabetes and its complications including endothelial dysfunction.

Keywords: Thiobarbituric acid reacting substances, Oxidized low-density lipoprotein, Hemoglobin A1c, Diabetes.

(C) 2017 The Authors. Published by Innovare Academic Sciences Pvt Ltd. This is an open access article under the CC BY license (http://creativecommons. org/licenses/by/4. 0/) DOI: http://dx.doi.org/10.22159/ajpcr.2017.v10i6.17814

\section{INTRODUCTION}

Diabetes mellitus is a group of common metabolic disorders that share the phenotype of hyperglycemia as a consequence of defect in insulin secretion and or insulin action [1,2]. The prevalence of diabetes is increasing the worldwide which need more measures for prevention and control [3]. Oxidative stress in diabetes, as in other ailments, is a result of the hyper-production of reactive oxygen forms on one hand and hypoactivity of antioxidative system on the other [4]. Numerous studies indicate that postprandial (PP) metabolic derangements, most notably hyperglycemia and hypertriglyceridemia, are exaggerated and prolonged in Type 2 diabetes and are important cardiovascular disease (CVD) risk factors since they induce oxidative stress and endothelial dysfunction [5].

Studies are notably conducted using a 75 g glucose load. It is also welldocumented that physiological variations in response to oral glucose load and a mixed meal exist. Hence, this study was undertaken to observe the effect of regular diet on oxidative stress levels in Type 2 diabetic patients.

\section{METHODS}

The study was conducted at Kasturba Medical College and Hospital, Mangalore. Protocol was approved by Institutional Ethics Committee. Informed consent was obtained from all the patients. Patients enrolled into the study were Type 2 diabetic patients of duration 5-15 years on oral hypoglycemics. Patients on insulin were excluded from the study. Patients were divided into two groups of 30 individuals each based on hemoglobin A1c (HbA1c) values (Group 1 with $\mathrm{HbA} 1 \mathrm{c} \leq 7.5 \%$ and the Group $2 \mathrm{HbA1c} \geq 7.6 \%$ ). A brief history of diabetes was taken and $5 \mathrm{ml}$ plain blood and $2 \mathrm{ml}$ fluoride blood was collected in sterile vacutainer from each subject in fasting as well as 2 hrs after mixed meal. Patients were provided a meal (breakfast) amounting approximately $300-500 \mathrm{kcal}$. They were allowed to choose the food of their liking but restricted to the calories. Approximate calorie content of common breakfast items available was considered. For example dosa (plain) - $120 \mathrm{kcal}$, idli ( 3 big) - 130 kcal, uttapam (2 big) - $330 \mathrm{Kcal}$, sambar (1/2 cup) - $105 \mathrm{kcal}$, bread ( 2 slices) - $60 \mathrm{kcal}$, and egg boiled (1) - $55 \mathrm{kcal}$. The samples were assayed for plasma glucose (PG), thiobarbituric acid reacting substances (TBARS), and oxidized low-density lipoprotein (ox-LDL).

Malondialdehyde estimation was done manually by TBARS method [6-8]. $0.5 \mathrm{ml}$ serum was precipitated with $2.5 \mathrm{ml}$ of $10 \%$ phosphotungstic acid. After standing for 10 minutes was centrifuged at $3000 \mathrm{~g}$ for 10 minutes. The sediment was suspended in $4 \mathrm{ml}$ distilled water. $4 \mathrm{ml}$ distilled water treated similarly was used as the blank. This was followed by addition of $0.5 \mathrm{ml}$ glacial acetic acid and $0.5 \mathrm{ml} 0.33 \%$ thiobarbituric acid. It was kept in a water bath at $97^{\circ} \mathrm{C}$ for 45 minutes. The tubes were cooled and $1 \mathrm{ml} 5 \mathrm{M} \mathrm{HCl}$ was added to the tubes to lower $\mathrm{pH}$ of the solution to $<2$ (1.6-1.7). The pink color was extracted with $5 \mathrm{ml}$ butanol. The butanol layer was transferred to a spectrophotometer cuvette. Absorbance was read at $535 \mathrm{~nm}$. TBARS $(\mu \mathrm{mol} / \mathrm{L})=\mathrm{A} \times \mathrm{V}_{\mathrm{s}} \times 1000 / \varepsilon \times \mathrm{V}_{\mathrm{t}}$, where, $\varepsilon$ (molar absorbance of TBARS) $=1.56 \times 10^{5}, A=A b s o r b a n c e, V_{s}=$ Volume of solution in cuvette, $V_{t}=$ Volume of serum. TBARS values were expressed as $\mu \mathrm{mol} / \mathrm{L}$. The oxLDL was done with simple precipitation method $[9,10]$.

Comparison between both groups was done using independent t-test and comparison within each group at two points of time was done using paired t-test.

\section{RESULTS}

Patients in Group 1 and Group 2 were comparable with respect to age and duration of disease. The mean calorie intake was also similar between the two groups (Table 1). Significant difference in mean fasting PG and mean PP-PG values were found. An increase in PP-PG by $60 \mathrm{mg} / \mathrm{dl}$ in Group 1 and nearly $78 \mathrm{mg} / \mathrm{dl}$ in Group 2 from the baseline values was noted. Poorly controlled Group 2 displayed significantly higher levels of 
all the mean glycemic indices measured (Table 2). Markers of oxidative stress TBARS and ox-LDL were measured in fasting and PP state and compared. Fasting values of TBARS were compared with PP within each group which showed a statistically significant increase in both groups. Such variation was not observed in the case of ox-LDL (Table 3 and Fig. 1).

Table 1: Age, duration of diabetes and calorie intake in both groups

\begin{tabular}{llll}
\hline Parameters & \multicolumn{2}{l}{ Mean \pm SD } & \multirow{2}{*}{ p value } \\
\cline { 2 - 3 } & Group-1 & Group-2 & \\
\hline Age (years) & $55.3 \pm 12.3$ & $54.6 \pm 11.4$ & $0.207^{\text {ns }}$ \\
$\begin{array}{l}\text { Duration of } \\
\text { diabetes (years) }\end{array}$ & $6.4 \pm 1.4$ & $6.9 \pm 2.7$ & $0.817^{\text {ns }}$ \\
Calorie intake (kcal) & $398.8 \pm 104.1$ & $440.2 \pm 120$ & $0.160^{\text {ns }}$ \\
\hline
\end{tabular}

Ns: Not significant, SD: Standard deviation

Table 2: Comparison of glycemic indices between the groups

\begin{tabular}{llll}
\hline Parameters & \multicolumn{2}{l}{ Mean \pm SD } & \multirow{2}{*}{ p value } \\
\cline { 2 - 3 } & Group-1 & Group-2 & \\
\hline HbA1c (\%) & $6.68 \pm 0.47$ & $8.86 \pm 1.17$ & $<0.001^{* * *}$ \\
FPG (mg/dl) & $120.9 \pm 18.07$ & $161.7 \pm 47.48$ & $<0.001^{* * *}$ \\
PP-PG (mg/dl) & $180.7 \pm 55.66$ & $240.5 \pm 82.23$ & $0.002^{* *}$ \\
\hline
\end{tabular}

**Highly significant, ${ }^{* * *}$ Very highly significant. FPG: Fasting plasma

glucose, PP-PG: Postprandial plasma glucose, SD: Standard deviation, HbA1c: Hemoglobin A1c

Table 3: Comparison of oxidative stress markers in fasting and postprandial states

\begin{tabular}{|c|c|c|c|c|}
\hline \multirow[t]{2}{*}{ Parameters } & \multicolumn{2}{|l|}{ Group-1 } & \multicolumn{2}{|l|}{ Group-2 } \\
\hline & $\begin{array}{l}\text { Mean } \\
\text { difference } \\
\text { (F vs. PP) }\end{array}$ & p value & $\begin{array}{l}\text { Mean } \\
\text { difference } \\
\text { (F vs. PP) }\end{array}$ & p value \\
\hline TBARS $(\mu \mathrm{mol} / \mathrm{L})$ & 2.729 & $<0.001^{* * *}$ & 2.046 & $<0.001^{* * *}$ \\
\hline ox-LDL $(\mu \mathrm{mol} / \mathrm{L})$ & 0.026 & $0.821^{\text {ns }}$ & 0.004 & $0.948^{\text {ns }}$ \\
\hline
\end{tabular}

***Very highly significant. ns: Not significant, F: Fasting, PP: Postprandial, TBARS: Thiobarbituric acid reacting substances, ox-LDL: Oxidized low-density lipoprotein

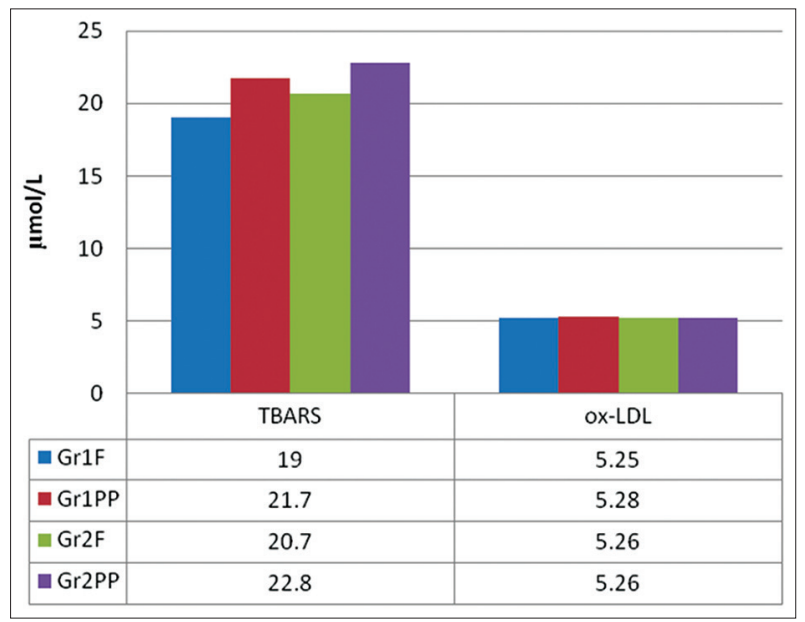

Fig. 1: Comparison of mean thiobarbituric acid reacting substances (TBARS) and oxidized low-density lipoprotein (ox-LDL) levels. Gr1F=Group 1 fasting state, Gr1PP=Group 1 postprandial state, Gr2F=Group 2 fasting state, Gr2PP=Group1 postprandial state

\section{DISCUSSION}

Correlation of HbA1c with both fasting and PP glucose is well proven [11-14]. In this study, both groups had PG levels comparable to their HbA1c values.

Mean PG showed a rise by $78 \mathrm{mg} / \mathrm{dl}$ in Group 2 from fasting to PP state. The rise was $18 \mathrm{mg} / \mathrm{dl}$ higher than that seen in Group 1 (60 mg/dl). This could be attributed to the result of poor glycemic control (mean HbA1c 8.8\%).

Studies by Ceriello et al. [15] in diabetics reported PP increase in PG, triglyceride TG, and TBARS after a standard meal. This study with regular diet also showed a significant increase in PP glucose and TBARS in both groups.

Studies have demonstrated a positive correlation between PP TBARS and TG [16-18] and that with PG [19]. This marker of oxidative stress has also been found to have a positive correlation with endothelial dysfunction [18].

High serum TG has been found to augment the oxidation of low-density lipoproteinLDL in fed state. Exaggerated LDL oxidation seen in PP state in diabetes may be a decisive contributor to CVD risk. Sensitivity of LDL to oxidation has been well studied in vitro and the maximal oxidation occurs at 120 minutes following the peak oxidative stimulus [20]. However, the time frame to measure peak ox-LDL in vivo has not been defined [21]. In this study, ox-LDL values were measured in fasting and $2 \mathrm{hrs}$ post meal and were found comparable. In animal studies, it was observed that after injecting highly oxidized and acetylated LDL intravenously, it disappeared from plasma within a matter of minutes indicating very short half-life. This reflects extremely rapid uptake of modified LDL by hepatic Kupffer cells and sinusoidal endothelial cells [22].

In this study, PP TBARS were high but contrary to this ox-LDL levels remained unaltered from their fasting values in both groups. Low PP ox-LDL levels despite a significant increase in mean PP TBARS levels could be attributed to short half-life of ox-LDL due to rapid uptake or longer time required for oxidation which needs further evaluation.

\section{CONCLUSION}

Regular diet with identical calorie intake has caused higher post prandial glycemia in poorly controlled Type 2 diabetes. Post meal oxidative stress as measured by TBARS was found to be present and greatly increased in Type 2 diabetes irrespective of glycemic control.

\section{REFERENCES}

1. Sulekha S, ManjrekarPA,HegdeA, Shenoy R. Meal induced dyslipidemia in Type 2 diabetes mellitus. Biomedicine 2014;34(1):137-41.

2. Jayesh BD, Snehal NM, Archana RJ. Diabetic nephropathy-genesis, prevention and treatment. Int J Pharm Pharm 2014;6(9):42-7.

3. Mosab A, Aisha S, Osama A. The association of Type 2 diabetes with obesity and other factors: In multinational community. Int J Pharm Pharm 2014;6(9):257-60.

4. Nesto RW. Beyond low density lipoprotein: Addressing the atherogenic lipid triad in Type 2 diabetes mellitus and the metabolic syndrome. Am J Cardiovasc Drugs 2005;5(6):379-87.

5. Suri RK, Guptha MM, Chakkravarthi AK. Hyperlipidemia and vascular populations of diabetes mellitus. J Assoc Physicians India 1979;27:505.

6. Wojciench W, Jean N, Anne P. Optimized steps in fluorometric determination of thiobarbituric acid reacting substances in serum: Importance of extraction $\mathrm{pH}$ and influence of sample preservative and storage. Clin Chem 1993;39(12):2522-6.

7. Poornima K, Cariappa M, Asha K, Kedilaya HP, Nandini M. Oxidant and antioxidant status in vegetarians and fish eaters. Indian $\mathrm{J}$ Clin Biochem 2003;18(2):197-205.

8. Wasowicz W, Neve J, Peretiz A. Optimized steps in fluorometric determination of thiobarbituric acid reactive substances in serum: Importance of extraction, $\mathrm{pH}$ and infuences of sample preservation and storage. Clin Chem 1993;39:2522-6. 
9. Scoccia AE, Molinuevo MS, McCarthy AD, Cortizo AM. A simple method to assess the oxidative susceptibility of low density lipoproteins. BMC Clin Pathol 2001;1(1):1.

10. Wieland H, Seidel D. A simple specific method for precipitation of low density lipoproteins. J Lipid Res 1983;24(7):904-9.

11. Sacks DB. Correlation between hemoglobin A1c (HbA1c) and average blood glucose: Can $\mathrm{HbA1c}$ be reported as estimated blood glucose concentration? J Diabetes Sci Technol 2007;1(6):801-3.

12. Múnera-Jaramillo MI, Restrepo-Lozada MA, Gómez-Bahamón LM, Mesa-Suarez Ddel R, Ramirez-Puerta BS. Glycosylated haemoglobin A1c compared to fasting plasma glucose in outpatients referred to a medical laboratory. Rev Salud Publica (Bogota) 2011;13(6):980-9.

13. Sikaris K. The correlation of hemoglobin A1c to blood glucose. J Diabetes Sci Technol 2009;3(3):429-38.

14. Kikuchi K, Nezu U, Shirakawa J, Sato K, Togashi Y, Kikuchi T, et al. Correlations of fasting and postprandial blood glucose increments to the overall diurnal hyperglycemic status in Type 2 diabetic patients: Variations with levels of HbA1c. Endocr J 2010;57(3):259-66.

15. Ceriello A, Bortolotti N, Motz E, Pieri C, Marra M, Tonutti L, et al. Meal-induced oxidative stress and low-density lipoprotein oxidation in diabetes: The possible role of hyperglycemia. Metabolism 1999;48(12):1503-8.

16. Saxena R, Madhu SV, Shukla R, Prabhu KM, Gambhir JK. Postprandial hypertriglyceridemia and oxidative stress in patients of Type 2 diabetes mellitus with macrovascular complications. Clin Chim Acta 2005;359(1-2):101-8.

17. Anderson RA, Evans LM, Ellis GR, Khan N, Morris K, Jackson SK, et al. Prolonged deterioration of endothelial dysfunction in response to postprandial lipaemia is attenuated by vitamin $\mathrm{C}$ in Type 2 diabetes. Diabet Med 2006;23(3):258-64.

18. Anderson RA, Evans LM, Ellis GR, Graham J, Morris K, Jackson SK, et al. The relationship between post-prandial lipaemia, endothelial function and oxidative stress in healthy individuals and patients with Type 2 diabetes. Atherosclerosis 2001;154(2):475-83.

19. Tushuizen ME, Nieuwland R, Scheffer PG, Sturk A, Heine RJ, Diamant M. Two consecutive high-fat meals affect endothelialdependent vasodilation, oxidative stress and cellular microparticles in healthy men. J Thromb Haemost 2006;4(5):1003-10.

20. Diwadkar VA, Anderson JW, Bridges SR, Gowri MS, Oelgten PR. Postprandial low-density lipoproteins in Type 2 diabetes are oxidized more extensively than fasting diabetes and control samples. Proc Soc Exp Biol Med 1999;222(2):178-84.

21. Wallace JP, Johnson B, Padilla J, Mather K. Postprandial lipaemia, oxidative stress and endothelial function: A review. Int J Clin Pract 2010;64(3):389-403.

22. Steinberg D. Low density lipoprotein oxidation and its pathobiological significance. J Biol Chem 1997;272(34):20963-6. 